\title{
miR-29b inhibits the progression of esophageal squamous cell carcinoma by targeting MMP-2
}

\author{
Y. QI ${ }^{1, *}, \mathrm{X} . \mathrm{LI}^{2, *}, \mathrm{~S} . \mathrm{ZHAO}^{1, *}$ \\ ${ }^{1}$ Department of Thoracic Surgery, the First Affiliated Hospital of Zhengzhou University, Zhengzhou, Henan 450052, P. R. China; ${ }^{2}$ Department \\ of Oncology, the First Affiliated Hospital of Zhengzhou University, Zhengzhou, Henan 450052, P. R. China \\ ${ }^{*}$ Correspondence: zhao_song2012@yahoo.com \\ ${ }^{*}$ Contributed equally to this work.
}

Received July 9, 2014 / Accepted November 3, 2014

\begin{abstract}
Accumulating evidence has shown that microRNAs (miRNAs) are aberrantly expressed in human esophageal cancer and crucial to tumorigenesis. Herein, we identified the role of miR-29b in esophageal squamous cell carcinoma (ESCC) development in vitro and in vivo. MiR-29b expression was investigated in thirty cases of ESCC samples as well as four ESCC cell lines by real-time PCR. Transwell assays were conducted to explore the effects of miR-29b on the invasion of human ESCC cell lines. The impact of overexpression of miR-29b on putative target MMP-2 were subsequently confirmed via Western blot. Our results indicated that MiR-29b expression was frequently down-regulated in ESCC specimens and cell lines compared with adjacent normal tissues $(p<0.05)$. Overexpression of miR-29b suppressed $(p<0.05)$ ESCC cell invasion, as well as the growth of xenograft tumors in mice. Overexpression of miR-29b significantly decreased $(p<0.05)$ the protein level of MMP-2, which has previously been identified as a direct target of miR-29b. Thus, our study demonstrated that overexpression of miR-29b inhibits tumor growth in part by targeting MMP-2. Our findings revealed that miR-29b may act as a tumor suppressor in ESCC, whose dysregulation may be involved in the initiation and development of human ESCC.
\end{abstract}

Key words: MiR-29b, esophageal squamous cell carcinoma, invasion, MMP-2

Esophageal squamous cell carcinoma (ESCC) is a major cause of mortality and morbidity in China and the 6th leading cause of cancer-related death worldwide [1,2]. Aggressive local invasion, early metastasis, and multidrug resistance (MDR) to chemotherapy are the main causes of treatment failure $[3,4]$. Histologically, there are two major types of esophageal cancer, each with distinct etiologic and pathologic characteristics: esophageal squamous cell carcinoma and adenocarcinoma. In spite of years of research, the pathogenesis of ESCC is still poorly understood $[5,6]$. Therefore, a better understanding of the molecular mechanism governing its growth and early diagnosis are particularly important.

MicroRNAs (miRNAs) are small noncoding RNAs of approximately 21-25 nucleotides that regulate the translation of mRNAs to proteins. Single-stranded miRNAs can bind messenger RNAs of potentially hundreds of genes at the 3' untranslated region, resulting in degradation or inhibition of the target messenger RNA $[7,8]$. Mature miRNAs play important regulatory roles in cell growth, proliferation, differentiation and cell death. Several studies have revealed that miRNAs play an important role in multiple aspects of carcinogenesis through function either as oncogenes or tumor suppressors $[9,10]$. Upregulated miRNAs in cancer may function as oncogenes by negatively regulating tumor suppressor genes. In contrast, down-regulated miRNAs may normally function as tumor suppressor genes and inhibit cancer by regulating oncogenes. It is reported that miRNAs are aberrantly expressed in several types of human cancer and these unique miRNA expression profiles for each cancer type would be a useful biomarker for cancer diagnosis and prognosis [11]. Among them, miR-29b was observed down-regulated in different types of cancer, including leiomyoma [12], endometrial [13], prostate [14], and ovarian cancer [15]. So far, the role of miR29b in the progression of esophageal carcinogenesis remains largely unknown. In addition, the secretion of matrix metalloproteinases (MMPs) is crucial in cancer cell metastasis, and closely correlated with the invasion behavior of cancer (16). Among these MMPs, MMP-2/9 are abundantly expressed in various malignant tumors including ESCC [17]. However, little is known about the relationship between the miR-29b and MMPs in ESCC development. 
In the present study, we discovered that the expression of miR-29b in ESCC tissues was lower than that of adjacent normal tissues. Meanwhile, Overexpression of miR-29b inhibited the invasion of ESCC cell lines as well as the growth of xenograft tumors in mice. Regulation of miR-29b expression affected MMP-2 in ESCC cell lines. Based on our results, we proved that miR-29b inhibits ESCC invasion in part by targeting MMP-2.

\section{Material and methods}

Clinical ESCC specimens. Fifteen pairs of primary esophageal squamous cell carcinoma and corresponding normal tissues, as well as other 98 cases of human ESCC tissues were obtained from patients who underwent primary surgical treatment at the First Affiliated Hospital of Zhengzhou University (Zhengzhou, China) from 2011 to 2013. All samples were histologically confirmed by staining with hematoxylin-eosin. Written consent of tissue donation for research purposes was obtained from each patient. The study protocol was approved by the Scientific and Ethical Committee of the First Affiliated Hospital of Zhengzhou University. The specimens were immediately frozen in liquid nitrogen and stored at $-80^{\circ} \mathrm{C}$.

The normal esophageal squamous epithelium was collected and finely minced, and then trypsinized at $37^{\circ} \mathrm{C}$ for $30 \mathrm{~min}$. The suspension was spun to collect the epithelial cells. The cells were incubated in Dulbecco's modified Eagle's medium (DMEM, Gibco, Grand Island, NY) with $1 \mathrm{mmol} / \mathrm{L}$ Na pyruvate (Cellgro, Herndon, VA), $2 \mathrm{mmol} / \mathrm{L}$ L-glutamine (Gibco), 5\% fetal calf serum (Gibco), 5mg/ml insulin(Gibco), 1.5ng/ml epidermal growth factor (Gibco) at $37^{\circ} \mathrm{C}$ in an atmosphere of $5 \% \mathrm{CO}_{2}$ at high humidity, and the media were changed every 48 hours. Cells growing in culture were identified for epithelial origin by morphological appearance and cytokeratins expression.

Cell lines and cell culture. All human ESCC cell lines (EC9706, KYSE150, KYSE180 and KYSE450) used in the present study were purchased from Cell Center of Shanghai Institute of Life Science, Chinese Academy of Science (Shanghai, China). All Cells were cultured in RPMI1640 medium (Gibco) supplemented with $10 \%$ fetal bovine serum (FBS; Hyclone, Logan, UT) and antibiotics (100 U/ml penicillin and $100 \mathrm{mg} / \mathrm{ml}$ streptomycin) in a humidified atmosphere containing $5 \% \mathrm{CO}_{2}$ at $37^{\circ} \mathrm{C}$.

Cell transfection. The miR-29b mimics and a nonspecific miR control (NC) were synthesized and purified by Genepharma Biotech (Shanghai, China). Cells were seeded into 6-well plates until $60 \%$ confluent and then transiently transfected with $40 \mathrm{nM}$ miR-29b mimics or NC using the Xtreme GENE Transfection Reagent (Roche, Indianapolis, IN) according to the manufacturer's instructions. After 48 hours of miRNA transfection, the cells were harvested for further experiments. For targeted knockdown of MMP2, cells were transfected with MMP2 specific siRNA and scrambled siRNA (OriGene Technologies Inc., Rockville, MD), then cells were harvested for Western blot analysis after 2, 4 days transfection. All experiments were performed in triplicate.
RNA isolation and real-time RT-PCR. Total RNA from tissues or cultured cells was extracted using TRIZOL reagent (Invitrogen Life Technologies) for miR-29b expression analyses. Total RNA was reverse transcribed to cDNA using a PrimeScript RT reagent kit (Takara, Dalian, China). Quantitative real-time PCR (qPCR) was performed using a SYBR Premix Ex Taq $^{\text {Tm }}$ II kit (Takara) on an ABI7900HT System. U6 small nuclear RNA was used as an internal control to normalize RNA input. Specific primers for miR-29b were 5'- TCG GTC CAG TTT TCC CAG -3'(sense) and 5'- AGT GCG TGT CGT GGA GTC -3' (antisense). Primer sequences for U6 were 5'- TGC GGG TGC TCG CTT CGG CAG C -3' (sense) and 5'- CCA GTG CAG GGT CCG AGG T -3’ (antisense). Gene expression

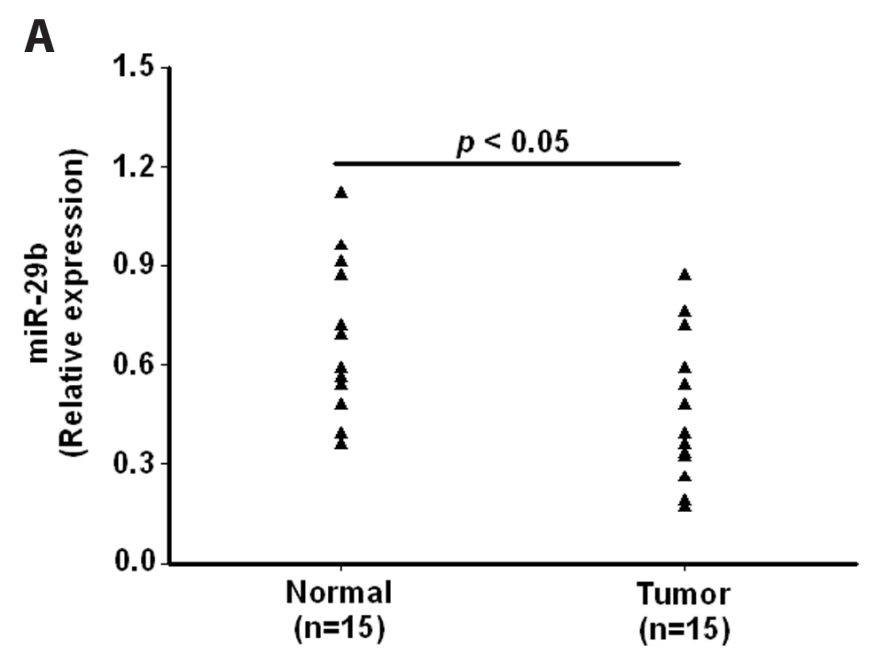

B

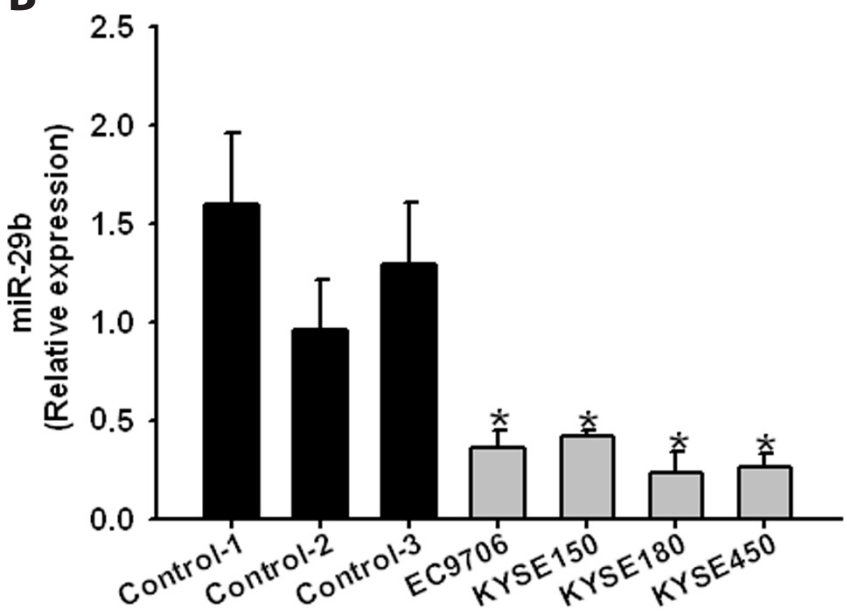

Figure 1. Decreased expression of miR-29b in both primary ESCC tissues and cell lines. (A) Decreased miR-29b expression in ESCC tissues compared to the adjacent normal tissues from a panel of 15 ESCC patients. (B) Significant loss of miR-29b expression in four ESCC cell lines in comparison with normal esophageal squamous epithelium from 3 healthy individuals. Data are presented as means \pm SEM. ${ }^{\star}$ Different $(p<0.05)$ from normal controls. 


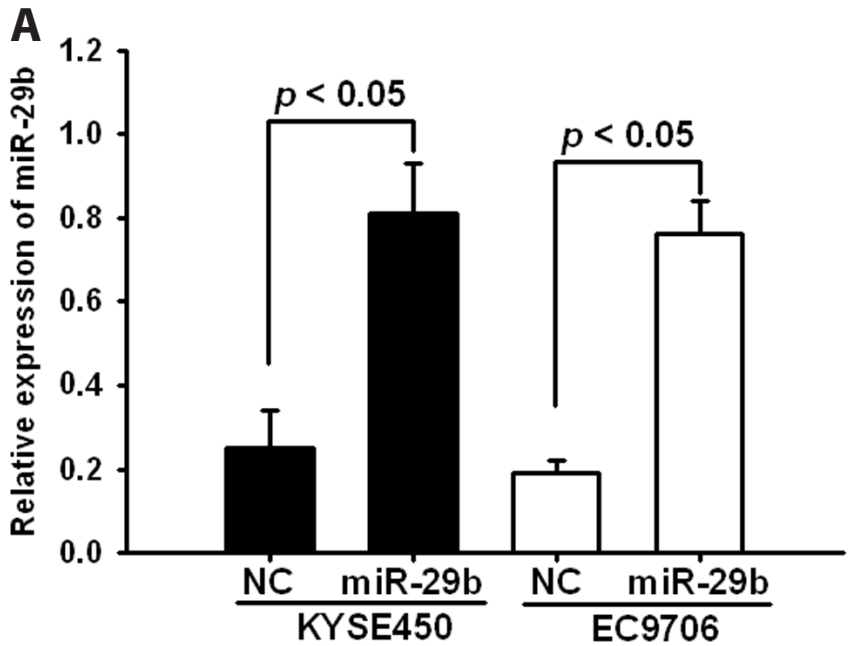

B
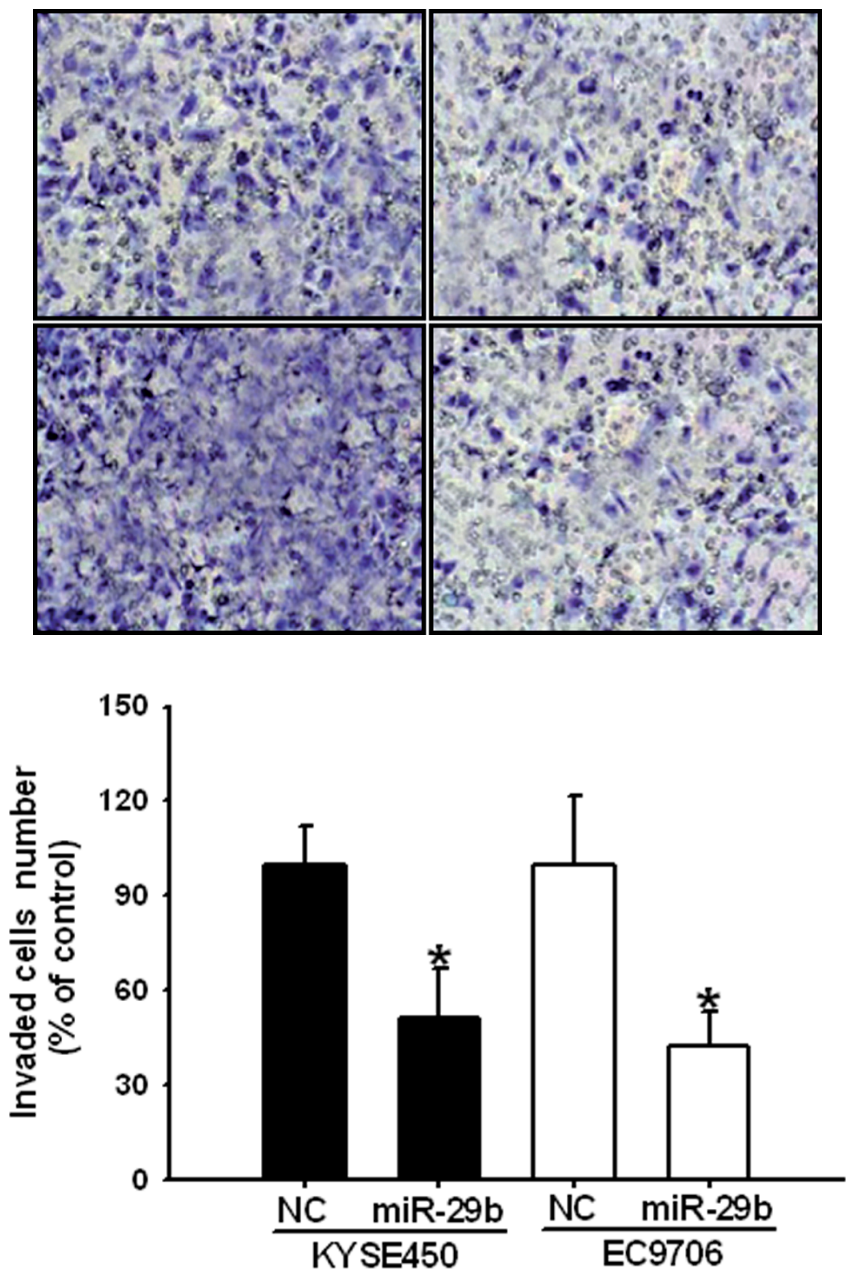

Figure 2. Effects of miR-29b overexpression on invasion of KYSE450 and EC9706 cells lines. (A) The expression level of miR-29b was detected by real-time PCR after $48 \mathrm{hr}$ transfection and normalized to that of U6. Data are presented as means \pm SEM. (B) The invasion activity of ESCC cells was performed using 24-well transwell chamber. Data are expressed as means \pm SEM from 4 independent experiments.. ${ }^{\star}$ Different $(p<0.05)$ from their controls, respectively. was normalized to internal controls and fold changes were calculated using relative quantification $(2-\Delta \Delta \mathrm{Ct})$.

Cell invasion assay. The Matrigel coated Boyden chamber (BD Biosciences, San Jose, CA) was used to evaluate the cell invasion of KYSE450 and EC9706 cells. Cells were plated in the 6-well plates and transfected with miR-29b mimics or NC. After $48 \mathrm{~h}$ transfection, cells were seeded onto the upper compartment of an invasion chamber coated with Matrigel. The lower compartment was filled with complete medium. The chamber was incubated at $37^{\circ} \mathrm{C}$ for $12 \mathrm{~h}$ and the filters were removed. Cells invaded on the bottom of inserts were fixed, stained, and counted under a microscope. The value of invasion activity was expressed as the average number of invaded cells per microscopic field over the 5 fields in each assay from four independent experiments.

Western blot analysis. After $48 \mathrm{~h}$ transfection with different concentrations of miR-29b mimics, cells were washed in ice-cold PBS and added to RIPA lysis and extraction buffer (Thermo Fisher Scientific, Franklin, MA) containing Protease Inhibitor Cocktail I (Millipore, Billerica, MA). The protein concentrations in the supernatants of the lysates were determined. Proteins (15-20 ug) were electrophoresed on SDSPAGE and transferred onto PVDF membranes. Proteins on the membranes were probed with the antibody against MMP-2/9 (1:2,000; Cell Signaling Technology, Inc., Danvers, MA) and GAPDH (1:5000; Kangchen, Shanghai, China). Western blot studies were run in at least three independent experiments.

Tumor growth assay. Female BALB/c nude mice aged 4 to 5 weeks were purchased from Laboratory Animal Services Centre of Zhengzhou University. Animal handling and experimental procedures were approved by the Animal Experimental Ethics Committee of the First Affiliated Hospital of Zhengzhou University. Mice ( $n=6$ /group) were injected with ESCC cells transfected with NC or miR-29b mimics. Mice tumor volume were measured every week by using a dial caliper. After 4 weeks of observation, the mice were sacrificed and tumors were obtained. The tumor weight was measured and tumor volume

Table 1. Correlation of miR-29b expression with clinical characteristics of ESCC

\begin{tabular}{llccc}
\hline Clinicopathological factors & $\begin{array}{c}\text { Total, } \\
(\mathrm{n}=98)\end{array}$ & $\begin{array}{c}\text { miR-29b } \\
\text { expression }\end{array}$ & $\begin{array}{c}\text { Significant } \\
(p<0.05)\end{array}$ \\
\hline Age & $<60$ & 48 & $0.44 \pm 0.041$ & NS \\
\multirow{3}{*}{ Gender } & $\geq 60$ & 50 & $0.47 \pm 0.064$ & \\
\multirow{4}{*}{ Tumor size } & Male & 59 & $0.47 \pm 0.076$ & NS \\
& Female & 39 & $0.43 \pm 0.063$ & \\
Clinical stage & $<3 \mathrm{~cm}$ & 44 & $0.47 \pm 0.056$ & NS \\
\multirow{4}{*}{ Lymph node metastasis } & $\geq 3 \mathrm{~cm}$ & 54 & $0.45 \pm 0.073$ & \\
& I+II & 40 & $0.50 \pm 0.066$ & NS \\
T stage & III+IV & 58 & $0.45 \pm 0.083$ & \\
& Pegative & 42 & $0.51 \pm 0.087$ & S \\
& Positive & 56 & $0.39 \pm 0.036$ & \\
& T1+T2 & 46 & $0.48 \pm 0.031$ & NS \\
& T3+T4 & 52 & $0.45 \pm 0.024$ & \\
\hline
\end{tabular}



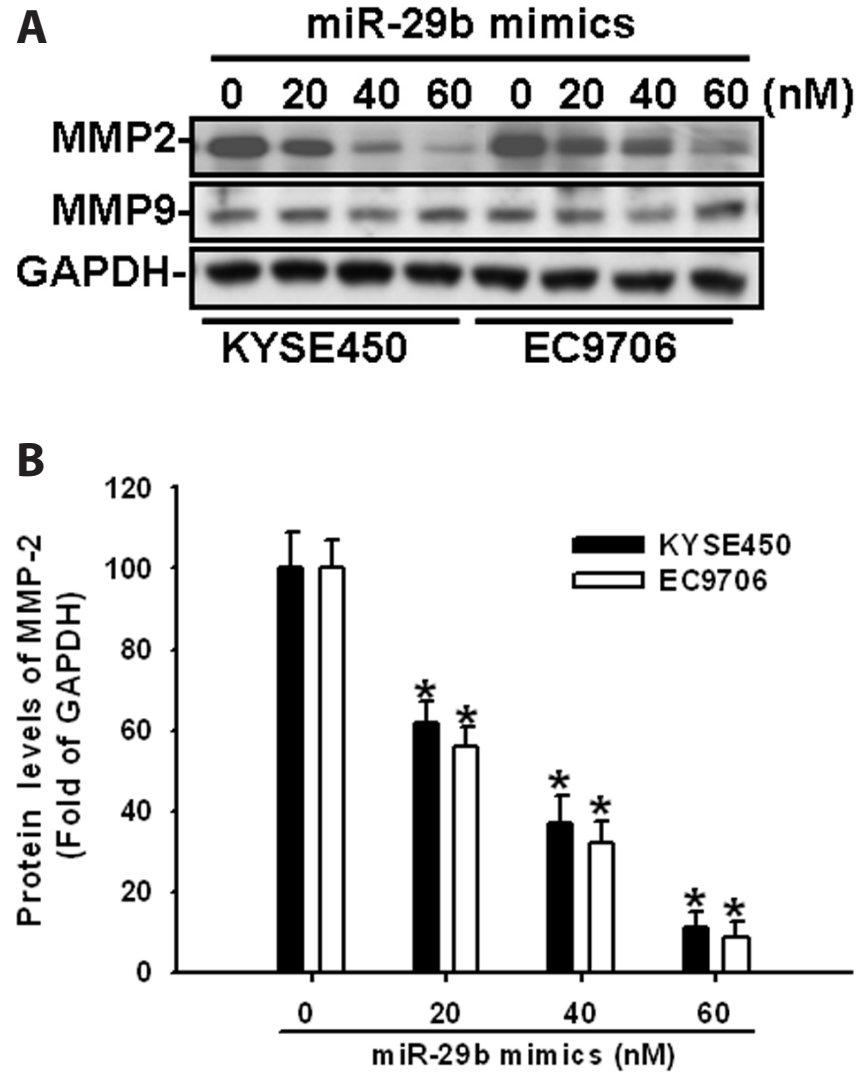

Figure 3. Overexpression of miR-29b decreased the protein levels of MMP-2, but not MMP-9. The protein levels of MMP-2/9 were detected by Western blot after transfected with different concentrations of miR$29 \mathrm{~b}$ mimics (A). The relative expression of MMP2 was normalized to the endogenous control GAPDH (B). Data are presented as means \pm SEM. ${ }^{*}$ Different $(p<0.05)$ from the control group.

was calculated according to the formula: tumor volume $\left(\mathrm{mm}^{3}\right)$ $=\pi / 6 \mathrm{x}$ length $(\mathrm{mm}) \mathrm{x}$ width $(\mathrm{mm})^{2}$

Statistical analysis. All values were expressed as means \pm SD. Correlations between miR29b expression and clinicopathological features were analyzed by Student's t-test between two groups. All values were expressed as means \pm S.E.M. Cell invasion and Western blot assays were tested using Student's t-test and one-way ANOVA, respectively. $p<0.05$ was considered to be statistically significant.

\section{Results}

MiR-29b was frequently down-regulated in clinical specimens and human ESCC cell lines. We firstly examined miR-29b expression levels in 30 frozen samples from ESCC patients (15 tumors and 15 adjacent normal controls) by TaqMan real time RT-PCR. Our results showed that miR-29b expression is significantly $(p<0.05)$ decreased in ESCC tissues in comparison with adjacent normal tissue (Fig.1A). Then, we further extended our test to four human ESCC cell lines. The results showed that
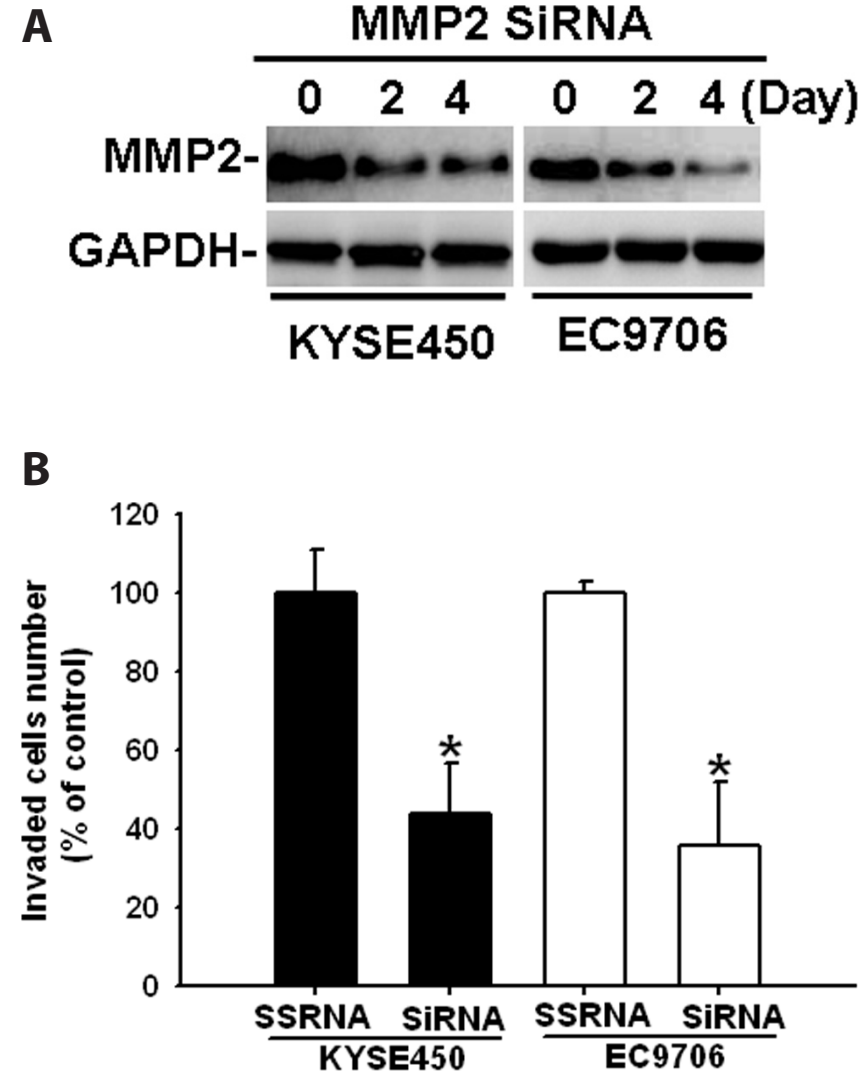

Figure 4. Effects of MMP-2 knockdown on cell invasion in KYSE450 and EC 9706 cells. (A) The protein levels of MMP-2 were detected by Western blot after transfected with MMP-2 specific siRNA in KYSE450 and EC9706 cells. (B) Quantified data of cell invasion are expressed as means \pm S.E.M. ${ }^{*}$ Different $(p<0.05)$ from the scrambled control.

the expression level of miR-29b was decreased $(p<0.05)$ in all 4 ESCC cell lines examined, compared with normal esophageal squamous epithelium from 3 healthy individuals. (Fig.1B). Meanwhile, we further investigated the correlation of miR-29b expression with clinical characteristics of ESCC. As shown in table 1 , low expression of miR-29b was significantly associated with lymph-node metastasis $(p<0.05)$.

Effect of miR-29b on ESCC cell invasion. To validate whether miR-29b regulated ESCC cell invasion, we performed a trans-well assay by transfecting miR-29b mimics or NC into KYSE450 and EC9706 cells. As shown in Fig.2A, the miR-29b levels were highly increased in both KYSE450 and EC9706 cells after transient transfection. As expected, the increased expression of miR-29b induced significant inhibition $(p<0.05)$ on cell invasion in both KYSE450 and EC9706 cells (Fig. 2B).

Overexpression of miR-29b reduced MMP2 protein level

To explore the mechanism of invasion inhibition induced by miR-29b, we investigated whether miR-29b could regulate MMP2 expression in KYSE450 and EC9706 cells. After transfected with miR-29b mimics at 4 different concentrations 

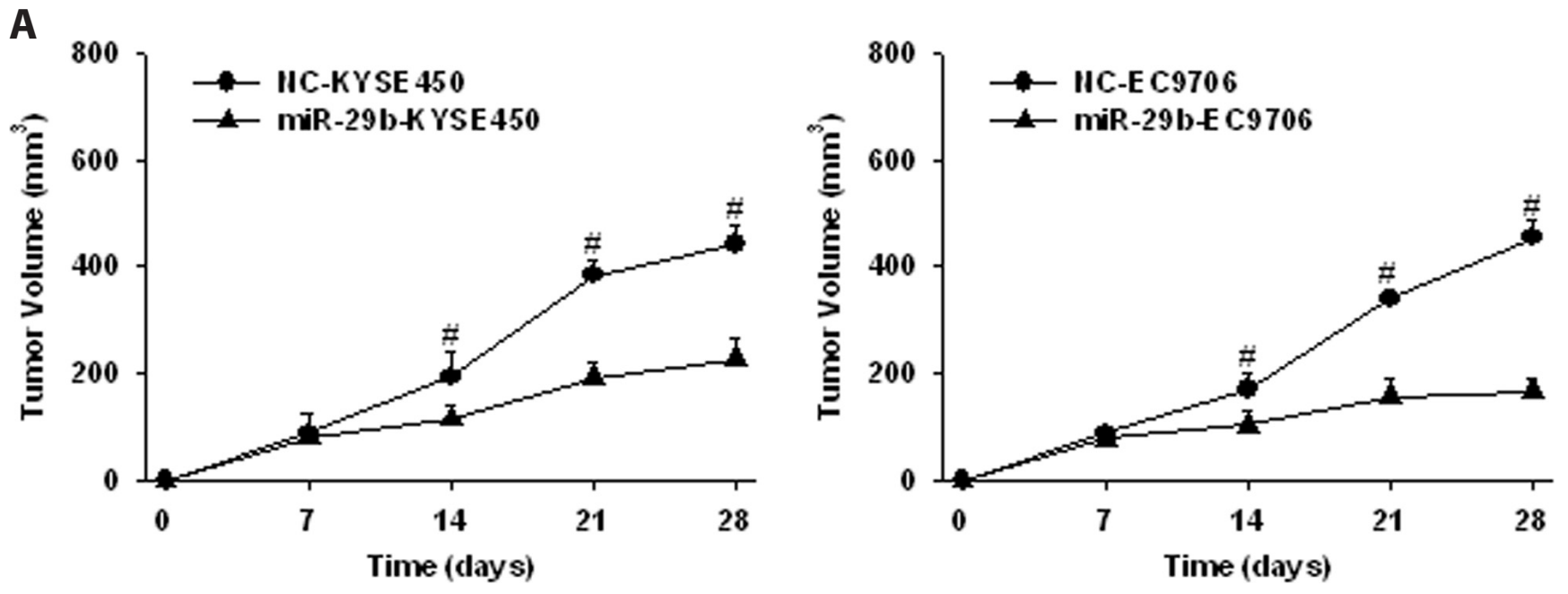

B

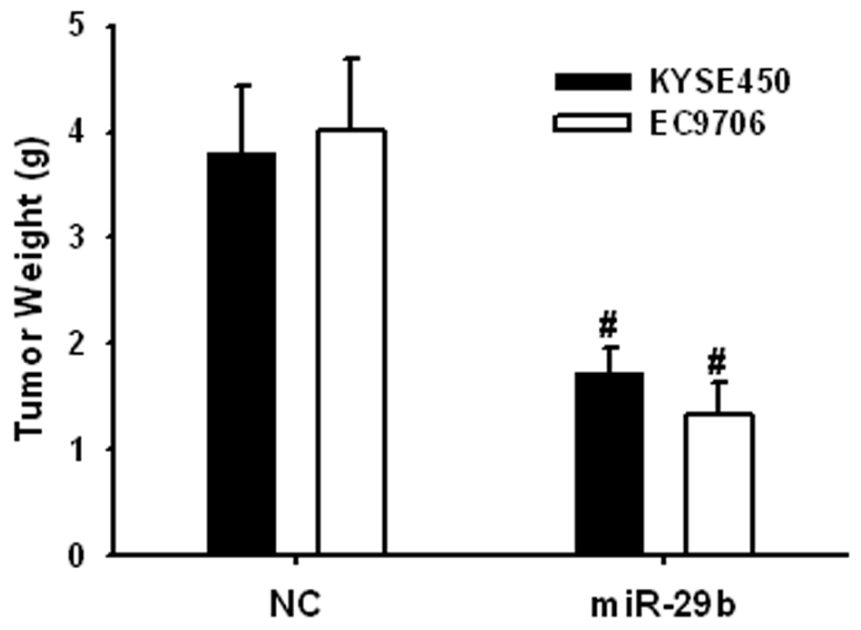

Figure 5. miR-29b inhibited tumor growth in vivo. Tumor cells transfected with miR-29b mimics or NC were injected subcutaneously in the flanks of nude mice, respectively $(\mathrm{n}=\mathbf{2 4})$. Tumor volume were measured every week by using a dial caliper $(\mathrm{A})$. After 28 days, tumors samples were carefully removed and tumor weight was measured (B). Data are presented as means \pm SEM. ${ }^{*}$ Different $(p<0.05)$ from the NC group.

(0, 20, 40,60 $\mathrm{nM})$ and then examined MMP2 expression levels. As shown in Fig. 3, overexpression of miR-29b led to a dosedependent $(p<0.05)$ decrease in MMP-2 protein level.

Knockdown of MMP2 inhibited ESCC cells invasion. In order to address the functional role of MMP2 in ESCC cell invasion, KYSE450 and EC9706 cells cells were transfected with MMP2 specific siRNA. Compared with scrambled control, MMP2 siRNA significantly reduced $(p<0.05)$ MMP2 protein expression, and this inhibitory effect maintained at least 4 days (Fig. 4A). As expected, knockdown of MMP2 significantly inhibited $(p<0.05)$ ESCC cells invasion in these two cell lines. (Fig. 4B).

MiR-29b suppressed tumorigenicity in vivo. To confirm the above findings, an in vivo tumor model was used. MiR-29b mimics-transfected KYSE450 and EC9706 cells, NC-transfected KYSE450 and EC9706 cells (NC) were injected separately into four groups of nude mice ( $n=6 /$ group). When compared with NC groups., the average tumor volume of miR-29b groups were markedly reduced (Fig. $5 \mathrm{~A} ; p<0.05$ ) at days 14, 21 and 28 after injection. Meanwhile, the average tumor weight was also significantly reduced in the miR-29b group (Fig. 5B; $p<0.05$ ), but no difference in body weight was found between the miR-29b-treated and the NC- treated mice (data not shown).

\section{Discussion}

In the present study, we observed a significant downregulation of miR-29b expression in human ESCC tissues and cell lines as compared with non-tumor tissues. Overexpression of miR-29b inhibited the invasion of ESCC cell lines in vitro and xenograft tumor growth in vivo. Moreover, we found that miR-29b directly targeted and down-regulated a key molecule involved in metastasis, MMP-2. Therefore, miR-29b was 
identified as a new metastatic suppressor and has potential as a new therapeutic target in metastatic ESCC.

Aberrant expression of miRNAs has been deeply involved in couple of human diseases, including cancer $[18,19]$. It was reported that the miR-29b expression was significantly downregulated in different types of cancer [12-15]. In agreement with these reports, our current study found that miR-29b was frequently down-regulated in ESCC clinical specimens and cell lines. Importantly, this low expression of miR-29b was significantly associated with lymph-node metastasis $(p<0.05)$. To reveal the functional roles of miR-29b in ESCC invasion, we ectopically raised the miR-29b level in ESCC cells to investigate its effect on cell invasion. Consistent with our expectation, increasing the expression level of miR-29b could obviously inhibit cell invasion in both KYSE450 and EC9706 cells, and suppress tumorigenesis in a murine model of ESCC xenograft, revealing its potential tumor suppressor role in ESCC development. These findings were similar to the investigation in human choriocarcinoma [20] and non-small cell lung cancer [21] that restoration of miR-29b expression inhibited cell invasion in these cancer cell lines.

The miR-29 family includs three members: miR-29a, miR$29 b$, and miR-29c, which display high sequence similarity and share a common sequence for target recognition [22,23].

Several studies have reported an inverse relationship regarding the expression of miR-29b and MMP-2 [24-26]. Meanwhile, miR databases (TargetScan and miRanda) also consider MMP-2 as a potential target of miR-29b. As an important member of matrix metalloproteinases family, MMP-2 plays important roles in physiological and pathological remodeling of the extracellular matrix (ECM) during tumor metastasis, activation of MMP-2 results in ECM degradation, which facilitates the invasion and metastasis of tumor cells [27-29]. Our current study demonstrated that the miR-29b suppression of MMP-2 is closely related to invasion and metastasis of ESCC. These findings were in agreement with several of recent reports that miR-29b is involved in the negative regulation of metastasis in couple of cancer types [25,30,31]. Combining these findings, expression level of miR-29b was inversely correlated with the metastatic potential of ESCC, which may contribute to inhibition of ESCC metastasis.

In summary, we proved that miR-29b was markedly downregulated in human ESCC tissue and cell lines. Increasing the expression of miR-29b may lead to ESCC cell invasion suppression in vitro through targeting MMP-2. Though there is still much to learn about the role of miR-29b in ESCC metastasis and tumorigenesis in vivo, miR-29b provides us with a new metastatic suppressor and has potential as a new therapeutic target in metastatic ESCC.

\section{References}

[1] LIN Y, TOTSUKA Y, HE Y, KIKUCHI S, QIAO Y, et al. Epidemiology of esophageal cancer in Japan and China. J Epidemiol 2013; 23: 233-42. http://dx.doi.org/10.2188/jea.JE20120162
[2] WHEELER JB, REED CE. Epidemiology of esophageal cancer. Surg Clin North Am 2012; 92: 1077-87. http://dx.doi. org/10.1016/j.suc.2012.07.008

[3] TOH Y, OKI E, OHGAKI K, SAKAMOTO Y, ITO S, et al. Alcohol drinking, cigarette smoking, and the development of squamous cell carcinoma of the esophagus: molecular mechanisms of carcinogenesis. Int J Clin Oncol 2010; 15: 135-44. http://dx.doi.org/10.1007/s10147-010-0057-6

[4] STONER GD, WANG LS. Chemoprevention of esophageal squamous cell carcinoma with berries. Top Curr Chem 2013; 329: 1-20.

[5] THALLINGER CM, KIESEWETTER B, RADERER M, HEJNA M. Pre- and postoperative treatment modalities for esophageal squamous cell carcinoma. Anticancer Res 2012; 32: 4609-27.

[6] STONER GD, WANG LS, CHEN T. Chemoprevention of esophageal squamous cell carcinoma. Toxicol Appl Pharmacol 2007; 224: 337-49. http://dx.doi.org/10.1016/j. taap.2007.01.030

[7] YOSHINO H, SEKI N, ITESAKO T, CHIYOMARU T, NAKAGAWA M, et al. Aberrant expression of microRNAs in bladder cancer. Nat Rev Urol 2013; 10: 396-404. http://dx.doi. org/10.1038/nrurol.2013.113

[8] FARAZI TA, HOELL JI, MOROZOV P, TUSCHL T. MicroRNAs in human cancer. Adv Exp Med Biol 2013; 774: 1-20. http://dx.doi.org/10.1007/978-94-007-5590-1 1

[9] BAER C, CLAUS R, PLASS C. Genome-wide epigenetic regulation of miRNAs in cancer. Cancer Res 2013; 73: 473-7. http://dx.doi.org/10.1158/0008-5472.CAN-12-3731

[10] MAYNE GC, HUSSEY DJ, WATSON DI. MicroRNAs and esophageal cancer--implications for pathogenesis and therapy. Curr Pharm Des 2013; 19: 1211-26.

[11] NANA-SINKAM SP, CROCE CM. Clinical applications for microRNAs in cancer. Clin Pharmacol Ther 2013; 93: 98-104. http://dx.doi.org/10.1038/clpt.2012.192

[12] QIANG W, LIU Z, SERNA VA, DRUSCHITZ SA, LIU Y, et al.Down-regulation of miR-29b is essential for pathogenesis of uterine leiomyoma. Endocrinology 2014; 155: 663-9. http:// dx.doi.org/10.1210/en.2013-1763

[13] HIROKI E, AKAHIRA J, SUZUKI F, NAGASE S, ITO K, et al. Changes in microRNA expression levels correlate with clinicopathological features and prognoses in endometrial serous adenocarcinomas. Cancer Sci 2010; 101: 241-9 http:// dx.doi.org/10.1111/j.1349-7006.2009.01385.x

[14] RU P, STEELE R, NEWHALL P, PHILLIPS NJ, TOTH K, et al. miRNA-29b suppresses prostate cancer metastasis by regulating epithelial-mesenchymal transition signaling. Mol Cancer Ther 2012; 11: 1166-73. http://dx.doi.org/10.1158/1535-7163. MCT-12-0100

[15] DAI F, ZHANG Y, CHEN Y. Involvement of miR-29b signaling in the sensitivity to chemotherapy in patients with ovarian carcinoma. Hum Pathol 2014; 45: 1285-93. http://dx.doi. org/10.1016/j.humpath.2014.02.008

[16] ROY R, YANG J, MOSES MA. Matrix metalloproteinases as novel biomarkers and potential therapeutic targets in human cancer. J Clin Oncol 2009; 27: 5287-5297. http://dx.doi. org/10.1200/JCO.2009.23.5556 
[17] GROBLEWSKA M, SIEWKO M, MROCZKO B, SZMITKOWSKI M. The role of matrix metalloproteinases (MMPs) and their inhibitors (TIMPs) in the development of esophageal cancer. Folia Histochem Cytobiol 2012; 50: 12-9. http://dx.doi.org/10.5603/FHC.2012.0002

[18] PLANK M, MALTBY S, MATTES J, FOSTER PS. Targeting translational control as a novel way to treat inflammatory disease: the emerging role of microRNAs. Clin Exp Allergy 2013; 43: 981-99. http://dx.doi.org/10.1111/cea.12135

[19] LE QUESNE J, CALDAS C. Micro-RNAs and breast cancer. Mol Oncol 2010; 4: 230-41. http://dx.doi.org/10.1016/j. molonc.2010.04.009

[20] LI P, GUO W, DU L, ZHAO J, WANG Y, et al. microRNA-29b contributes to pre-eclampsia through its effects on apoptosis, invasion and angiogenesis of trophoblast cells. Clin Sci (Lond) 2013; 124: 27-40. http://dx.doi.org/10.1042/CS20120121

[21] WU DW, HSU NY, WANG YC, LEE MC, CHENG YW, et al. c-Myc suppresses microRNA-29b to promote tumor aggressiveness and poor outcomes in non-small cell lung cancer by targeting FHIT. Oncogene 2014 Jun 9 ; 0. doi: 10.1038/onc.2014.152. [Epub ahead of print] http://dx.doi. org/10.1038/onc.2014.152

[22] KRIEGEL AJ, LIU Y, FANG Y, DING X, LIANG M. The miR29 family: genomics, cell biology, and relevance to renal and cardiovascular injury. Physiol Genomics 2012; 44: 237-44. http://dx.doi.org/10.1152/physiolgenomics.00141.2011

[23] SCHMITT MJ, MARGUE C, BEHRMANN I, KREIS S. MiRNA-29: a microRNA family with tumor-suppressing and immune-modulating properties. Curr Mol Med 2013; 13: 572-85. http://dx.doi.org/10.2174/1566524011313040009

[24] CHEN KC, WANG YS, HU CY, CHANG WC, LIAO YC, et al. OxLDL up-regulates microRNA-29b, leading to epigenetic modifications of MMP-2/MMP-9 genes: a novel mechanism for cardiovascular diseases. FASEB J 2011; 25: 1718-28. http:// dx.doi.org/10.1096/fi.10-174904

[25] STEELE R, MOTT JL, RAY RB. MBP-1 upregulates miR-29b that represses Mcl-1, collagens, and matrix-metalloproteinase-2 in prostate cancer cells. Genes Cancer. 2010; 1:381-387. http://dx.doi.org/10.1177/1947601910371978

[26] OKAMOTO K, MIYOSHI K, MURAWAKI Y. miR-29b, miR205 and miR-221 enhance chemosensitivity to gemcitabine in HuH28 human cholangiocarcinoma cells. PLoS One 2013; 8: e77623. http://dx.doi.org/10.1371/journal.pone.0077623

[27] KLEINER DE, STETLER-STEVENSON WG. Matrix metalloproteinases and metastasis. Cancer Chemother Pharmacol 1999; 43 Suppl: S42-51 http://dx.doi.org/10.1007/ $\underline{\mathrm{s} 002800051097}$

[28] YOSHIZAKI T, SATO H, FURUKAWA M. Recent advances in the regulation of matrix metalloproteinase 2 activation: from basic research to clinical implication. Oncol Rep 2002; 9: 607-11.

[29] CHIEN MH, LIN CW, CHENG CW, WEN YC, YANG SF. Matrix metalloproteinase-2 as a target for head and neck cancer therapy. Expert Opin Ther Targets 2013; 17: 203-16. http://dx.doi.org/10.1517/14728222.2013.740012

[30] CHOU J, LINJH, BRENOT A, KIM JW, PROVOT S, et al.. GATA3 suppresses metastasis and modulates the tumour microenvironment by regulating microRNA-29b expression. Nat Cell Biol 2013; 15: 201-13. http://dx.doi.org/10.1038/ $\underline{\text { ncb2672 }}$

[31] POUDYAL D, CUI X, LE PM, HOFSETH AB, WINDUST A, et al. A key role of microRNA-29b for the suppression of colon cancer cell migration by American ginseng. PLoS One 2013; 8: e75034. http://dx.doi.org/10.1371/journal.pone.0075034 